\title{
CORRIGENDUM
}

\section{The proto-oncoprotein KR-POK represses transcriptional activation of CDKN1A by MIZ-1 through competitive binding}

KM Lee, WI Choi, DI Koh, YJ Kim, BN Jeon, JH Yoon, CE Lee, SH Kim, J Oh and MW Hur

Oncogene (2017) 36, 4951; doi:10.1038/onc.2017.115; published online 12 June 2017

Correction to: Oncogene (2012) 31, 1442-1458; doi:10.1038/onc. 2011.331; published online 1 August 2011

Since the online publication of this article the authors noticed that in Acknowledgements a grant number of Faculty Research Grant from Yonsei University School of Medicine is missing.

The correct Acknowledgements should be:
'This work was mainly funded by a Basic Science Research Grant (314-2008-1-E00030 to MW Hur and CE Lee) and MRC (R13-2002054-05002-0) from the National Research Foundation of Korea, and also by a Faculty Research Grant (6-2007-0105 to MW Hur) from Yonsei University School of Medicine.'

The authors would like to apologize for this error. 